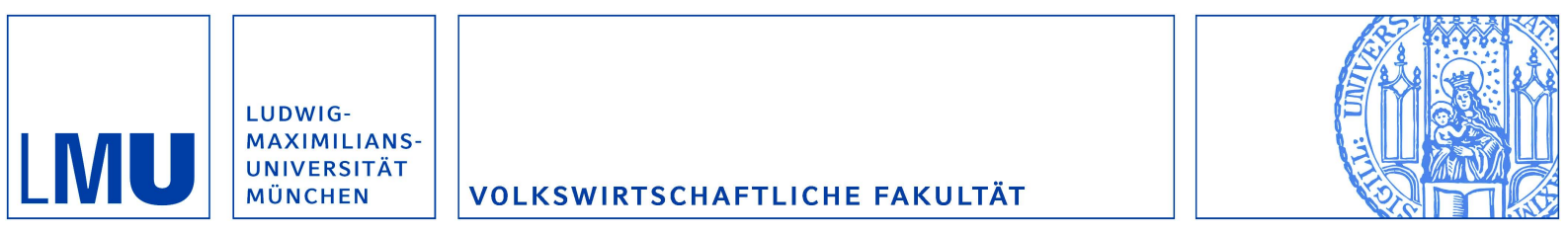

Kocher, Martin G.; Lahno, Amrei Marie und Trautmann, Stefan T.:

Ambiguity aversion is the exception

Munich Discussion Paper No. 2015-2

Department of Economics

University of Munich

Volkswirtschaftliche Fakultät

Ludwig-Maximilians-Universitä† München

Online at https://doi.org/10.5282/ubm/epub.23817 


\title{
Ambiguity aversion is the exception
}

\author{
Martin G. Kocher ${ }^{1}$, Amrei Marie Lahno ${ }^{2}$ \& Stefan T. Trautmann, ${ }^{3, *}$ \\ ${ }^{1}$ University of Munich, Germany; University of Gothenburg, Sweden; and Queensland \\ University of Technology, Australia \\ ${ }^{2}$ University of Munich, Germany \\ ${ }^{3}$ University of Heidelberg, Germany
}

\begin{abstract}
An extensive literature has studied ambiguity aversion in economic decision making, and how ambiguity aversion can account for empirically observed violations of expected utility-based theories. Almost all relevant applied models presume a general dislike of ambiguity. In this paper, we provide a systematic experimental assessment of ambiguity attitudes in different likelihood ranges and in the gain domain, the loss domain and with mixed outcomes. We draw on a unified framework with more than 500 participants and find that ambiguity aversion is the exception, not the rule. We replicate the usual finding of ambiguity aversion for moderate likelihood gains. However, when introducing losses or lower likelihoods, we observe either ambiguity neutrality or even ambiguity seeking behavior. Our results are robust to different elicitation procedures.
\end{abstract}

KEYWORDS: ambiguity aversion, decision under uncertainty, Ellsberg experiments JEL CLASSIFICATIONS: C91, D81

\footnotetext{
*Corresponding author: Alfred-Weber-Institute for Economics, University of Heidelberg, Bergheimer Str. 58 (Room 01.029), 69115 Heidelberg, Germany, Phone: +49 622154 2952, Fax: +49 622154 3592; email: trautmann@uni-hd.de. We thank seminar audiences at Tilburg Social Psychology, the University of Arizona, the Max-Planck-Institute of Economics at Jena, Queensland University of Technology at Brisbane, the ESA Asia-Pacific Meeting at Auckland, CATIE at Turrialba, the University of Innsbruck, the EWEBE Meeting at King's College London, EUI at Florence, the University of Salzburg, the University of Copenhagen, the University of Munich, the University of Queensland, the University of Sydney, the American Risk and Insurance Association Meeting at Seattle, and the University of Zurich for useful comments and suggestions. We are also grateful for the hospitality and the support by the Center for Advanced Studies at the University of Munich.
} 


\section{Introduction}

In decision under uncertainty, risky prospects with known probabilities are often distinguished from ambiguous prospects with unknown or uncertain probabilities. Inspired by a classic article by Ellsberg (1961), it is typically assumed that people dislike ambiguity in addition to a potential dislike of risk, and that they adjust their behavior in favor of known-probability risks, even at significant costs. A large literature has studied the consequences of such ambiguity aversion for decision making in the presence of uncertainty. Building on decision theories that assume ambiguity aversion, this literature shows that ambiguity can account for empirically observed violations of expected utilitybased theories ("anomalies"). In financial economics, ambiguity aversion has been employed to explain phenomena such as the equity premium and risk-free rate puzzles (Collard et al. 2011; Gollier 2011; Ju and Miao 2012; Maenhout 2004), and the stock market participation puzzle (Dow and Werlang 1992; Easley and O'Hara 2009). Alary et al. (2013) and Snow (2011) show that ambiguity aversion influences optimal insurance take-up, deductible choice, and self-protection activities. In health economics, Berger et al. (2013) find that ambiguity about the diagnosis or the treatment of a medical condition affects patients' treatment choices, while Hoy et al. (2014) explain the low take-up of costless genetic tests by ambiguity aversion. Ambiguity aversion has also been employed in economic models of climate change to motivate rapid emission cuts (Farber 2011; Millner et al. 2013). Many of these results have served to motivate regulation and policy (Farber 2011).

These and many other theoretical contributions presume a universally negative attitude toward ambiguity. Such an assumption seems, at first sight, descriptively justified on the basis of a large experimental literature following Ellsberg's original article. A sizable number of experimental studies have implemented an urn-choice experiment, whose design was proposed by Ellsberg to identify ambiguity attitudes (see section 2), and have predominantly found evidence for ambiguity aversion. However, as Ellsberg (2011) argues in a recent commentary on the occasion of the $50^{\text {th }}$ anniversary of his seminal article, the predominance of ambiguity aversion in experimental findings might be due to a narrow focus on the domain of moderate likelihood gains, as in his original examples. While fear of a bad unknown probability might prevail in this domain, people 
might be more optimistic in other domains, hoping for ambiguity to offer better odds than a known-risk alternative.

Notably, many of the theoretical contributions in economics and finance mentioned above concern applications in which unlikely events and loss outcomes are important. If likelihood and domain are relevant determinants of ambiguity attitudes, there is a potential mismatch between empirical evidence and theoretical interpretation. The existing experimental evidence on ambiguity attitudes for losses and for rare events indicates ambiguity aversion in the domain of low likelihood losses; for moderate likelihood gains and low likelihood losses ambiguity seeking is sometimes reported (see Trautmann and van de Kuilen, 2014, for an overview). While the basic Ellsberg paradigm is easy to implement and has consequently been studied in hundreds of experiments, conducting experiments with losses and identifying ambiguity attitudes for low likelihood events is complex and fewer studies have considered the loss and low-likelihood domains. Importantly, the complexity in implementing these domains in experiments has led to significant design heterogeneity across domains, which could potentially explain any differences in observed attitudes. Of the relatively low number of studies on domains beyond the standard Ellsberg setup, none considered all four domains within an identical design in terms of financial incentives and elicitation procedures (see Appendix A.1 for an overview of existing studies that report on all four domains and Table A1 for their design features). Given the importance of ambiguity attitudes for economic theorizing and policy, a careful measurement of these attitudes across the gain and loss domains, and across the low and moderate likelihood ranges is warranted.

In this paper, we provide a systematic assessment of ambiguity attitudes in different likelihood ranges and in the gain domain, the loss domain, and with mixed outcomes, i.e. where both gains and losses may be incurred. We draw on a unified experimental framework that allows comparing the relevant parameters, and we use different elicitation methods to address potential measurement effects on results. Our between-subjects design with more than 500 experimental participants exposes participants to exactly one of the four domains, reducing any contrast effects that may affect the preferences in the laboratory context. 
Our main result can be summarized in one sentence: Ambiguity aversion is the exception, not the rule. We replicate the finding of ambiguity aversion for moderate likelihood gains in the classic Ellsberg (1961) two-color design. However, once we move away from the gain domain or from the two-color choice to more colors, thus introducing lower likelihoods, we observe either ambiguity neutrality or even ambiguity seeking behavior. These results are robust to the elicitation procedure.

Our rejection of universal ambiguity aversion does not generally contradict ambiguity models, but it has important implications for the assumptions in applied models that use ambiguity attitudes to explain real-world phenomena. Theoretical analyses should not only consider the effects of ambiguity aversion, but also potential implications of ambiguity loving for economics and finance, particularly in contexts that involve rare events or perceived losses such as with insurance or investments. Policy implications should always be fine-tuned to the specific domain, because policy interventions based on wrong assumptions regarding the ambiguity attitudes of those targeted by the policy could be detrimental.

The rest of the paper is organized as follows. The next section presents the design of the tasks and incentives. We have been careful in minimizing differences across domains and in minimizing potential biases that could have led to ambiguity seeking results in previous studies. Section 3 describes basic properties of our experimental data, and section 4 presents results for the pure outcome domains (either gain or loss) for low and medium likelihoods. Section 5 provides results for mixed prospects. In section 6 , we discuss our findings and their implications for the modeling of ambiguity attitudes.

\section{Measurement of Ambiguity Attitudes}

\subsection{Prospects, Domains, and Predictions}

We elicit attitudes toward uncertain prospects defined on the outcome domain of gains or losses, and involving either low or moderate likelihoods. Participants make choices between ambiguous prospects and risky prospects. A risky prospect that pays €x with probability $\mathrm{p} \in[0,1]$ and $€ y$ otherwise is denoted $\mathrm{x}_{\mathrm{p}} \mathrm{y}$. An ambiguous prospect that pays $€ \mathrm{x}$ if event $\mathrm{E}$ occurs and $€ \mathrm{y}$ otherwise is denoted $\mathrm{x}_{\mathrm{E}} \mathrm{y}$. Ambiguity attitudes are identified by comparing participants' preferences between risky prospect $\mathrm{x}_{\mathrm{p}} \mathrm{y}$ and ambiguous prospect 
$\mathrm{X}_{\mathrm{E}} \mathrm{y}$, where $\mathrm{E}$ is defined such that exchangeability of events implies that the subjective probability $\mathrm{B}(\mathrm{E})$ equals $\mathrm{p}$. In particular, the ambiguous prospects are implemented as bets on the color of colored chips drawn from an opaque bag with an unknown distribution of colors, but with the participant being indifferent between betting on either of these colors. Details on the procedure used in the laboratory are given in section 2.3.

Table 1: Experimental Treatments in a Between-subjects Design

\begin{tabular}{cccccc}
\hline \hline Treatment & $\begin{array}{c}\text { Outcome } \\
\text { domain }\end{array}$ & $\begin{array}{c}\text { (Subjective) } \\
\text { probability }\end{array}$ & $\begin{array}{c}\text { \# colors used to } \\
\text { implement } \\
\text { ambiguous } \\
\text { events }\end{array}$ & $\begin{array}{c}\text { Expected } \\
\text { value of risky } \\
\text { prospect }\end{array}$ & $\begin{array}{c}\text { Predicted } \\
\text { attitude }\end{array}$ \\
\hline 20.50 & Gain & $\mathrm{p}=.5$ & 2 & 10 & AA \\
$(-20)_{.5} 0$ & Loss & $\mathrm{p}=.5$ & 2 & -10 & AS \\
20.10 & Gain & $\mathrm{p}=.1$ & 10 & 2 & AS \\
$(-20) .10$ & Loss & $\mathrm{p}=.1$ & 10 & -2 & AA \\
$(-10) .510$ & Mixed & $\mathrm{p}=.5$ & 2 & 0 & (AA) \\
$(-10) .110$ & Mixed & $\mathrm{p}=.1$ & 10 & 8 & (AA) \\
$10.1(-10)$ & Mixed & $\mathrm{P}=.1$ & 10 & -8 & (AA) \\
\hline \hline
\end{tabular}

Notes: a: risky prospect shown in choice between this risky prospect and the analogous ambiguous prospect; b: based on pattern observed in the literature; $\mathrm{AA}=$ ambiguity aversion; $\mathrm{AS}=$ ambiguity seeking.

In the experiment, we implement either moderate likelihood events with $\mathrm{p}=.5$, or low likelihood events with $\mathrm{p}=.1$. The outcomes $\mathrm{x}$ and $\mathrm{y}$ vary across experimental conditions. In treatments with pure outcome domains, $x$ equals either $€ 20$ in the gain conditions, or $-€ 20$ in the loss conditions, while y always equals $€ 0$. In treatments with mixed prospects, $x$ equals $€ 10$ and y equals $€ 10$, or vice versa. All conditions are shown in the first three columns of Table 1, which defines the conditions in terms of the properties of the risky prospect employed in the comparison between risk and ambiguity. The last column of Table 1 shows our predictions, as derived from the pattern identified in the existing literature (e.g., Trautmann and van de Kuilen 2014). We predict a fourfold pattern of ambiguity attitudes, with ambiguity aversion for moderate-likelihood gain and low-likelihood loss prospects, and ambiguity seeking for moderate-likelihood loss and low-likelihood gain prospects. No evidence exists on the mixed outcome domain; thus the 
canonical assumption of ambiguity aversion is our benchmark prediction for the mixed prospects.

\subsection{Measurement}

We measure ambiguity attitudes in a between-subjects design with each subject participating in exactly one of the seven treatments shown in Table 1. Our preference elicitation procedures are designed to minimize (and control for) potential biases due to the measurement method itself. To this end, we measure attitudes in two stages. In stage 1, we elicit a direct binary choice between a risky prospect and its matched ambiguous prospect. While this choice provides the simplest test of ambiguity attitudes and involves basically no design issues, it allows us to only categorize subjects into ambiguity averters and ambiguity seekers (with neutrals potentially included in both categories), without being able to assess the strength of these preferences.

In stage 2, we then elicit probability equivalents q for the ambiguous prospect: we find the risky prospect $\mathrm{x}_{\mathrm{q}} \mathrm{y}$ such that the participant is indifferent between the prospect $\mathrm{x}_{\mathrm{q}} \mathrm{y}$ and $\mathrm{x}_{\mathrm{E}} \mathrm{y}$. Note that if attitudes are not ambiguity neutral, $\mathrm{B}(\mathrm{E})$ implied by exchangeability need not be equal to q. Differences in $\mathrm{q}$ across subjects allow us to identify ambiguity attitudes more precisely. In particular, for gain prospects, a smaller $\mathrm{q}<\mathrm{B}(\mathrm{E})$ implies stronger ambiguity aversion as the decision maker is willing to accept a lower known chance of a gain in exchange for the unknown chance implied by E. For loss prospects, a larger $\mathrm{q}>\mathrm{B}(\mathrm{E})$ implies stronger ambiguity aversion as the decision maker is willing to accept a larger known chance of a loss in exchange for the unknown chance implied by E.

We elicit probability equivalents using a choice list consisting of nine binary choices, where choice $i$ elicits the preference between the ambiguous prospect $\mathrm{x}_{\mathrm{E}} \mathrm{y}$ and a risky prospect $\mathrm{x}_{\mathrm{qi}} \mathrm{y}$. The known probability $\mathrm{q}_{\mathrm{i}}$ increases when going down the list of choices, while the outcomes $\mathrm{x}$ and $\mathrm{y}$, and event $\mathrm{E}$ remain constant across choice items $i$. Table 2 shows the probabilities $\mathrm{q}_{\mathrm{i}}$ used in the choice lists for moderate and for low likelihood events.

When going through the list, a participant is presented with choices in which the known-risk prospect is initially very unattractive (for gains; opposite reasoning for 
losses), and subsequently becomes more attractive. If the initial risky prospect is less attractive than the ambiguous prospect and the ninth risky prospect is more attractive than the ambiguous prospect (vice versa for losses), there will be a probability $q_{i}$ at which the decision maker is indifferent between the two prospects. We use the choice item at which the participant switches from a preference for ambiguous to a preference for risky to approximate her probability equivalent. Formally, for a subject who switches to the risky prospect after item $i \in\{0,1,2, \ldots, 9\}$ the probability equivalent $\mathrm{q}$ is given by

$$
\mathrm{q}=\left\{\begin{array}{c}
q_{1}-\frac{1}{2}\left(q_{2}-q_{1}\right) \quad \text { if } i=0 ; \\
\frac{1}{2}\left(q_{i+1}+q_{i}\right) \quad \text { if } i \in\{1,2, \ldots, 8\} \\
q_{9}+\frac{1}{2}\left(q_{9}-q_{8}\right) \quad \text { if } i=9 ;
\end{array}\right.
$$

where $i=0$ means that the participant chooses the risky prospect already in the first choice option, and $i=9$ means that she never switched to the risky prospect. Hence, we take the midpoint between probabilities as an estimate for the probability equivalent, or, if necessary, extrapolate a probability equivalent at the boundaries of the choice list. ${ }^{1}$

While the binary choices in stage 1 should not be prone to biases caused by the elicitation procedure, elicitation procedures that measure the strengths of preferences are typically affected by design choices. Our choice list design used to measure probability equivalents intends to minimize design-driven biases, while accounting for the prior evidence and the structural differences between low and moderate likelihood prospects. Thus, we included the direct choice between $\mathrm{x}_{\mathrm{E}} \mathrm{y}$ and $\mathrm{x}_{\mathrm{p}} \mathrm{y}$ roughly in the middle of the choice list, skewing the list modestly toward the direction of ambiguity aversion for modest likelihood prospects and toward ambiguity seeking for low likelihood prospects. Such a setups aims to reduce biases resulting from highly skewed choice lists for low likelihood prospects relative to modest likelihood prospects, while at the same time

\footnotetext{
${ }^{1}$ In a third stage of the experiment we also elicited certainty equivalents for the risky prospect $\mathrm{x}_{\mathrm{p}} \mathrm{y}$ as an individual measure of risk attitude. We observe the typical reflection effects between gains and losses, and overweighting of small and underweighting of large probabilities. In particular, we find significant risk aversion for gains with moderate likelihoods and for losses with low likelihoods; and significant risk seeking for the mirrored domains and likelihoods. We do not observe any significant correlations between ambiguity and risk attitudes, similar to findings reported by Cohen et al. (1987), Di Mauro and Maffioletti (2004), or Levy et al. (2010).
} 
reducing the risk of having many subjects at the boundary of the choice lists by disregarding the previous evidence. In particular, because some previous studies reported probability equivalents in the range of $\mathrm{q}=.3$ for modest $(\mathrm{p}=.5)$ and $\mathrm{q}=.2$ for low likelihood ( $p=.1$ ) prospects (Trautmann and van de Kuilen 2014), we wanted the choice list to cover these values away from the boundaries of the list.

Table 2: Elicitation Tasks for Ambiguity Attitudes

\begin{tabular}{ccc}
\hline \hline & \multicolumn{2}{c}{ Prob. $\mathrm{q}_{\text {i }}$ conditional on baseline } \\
likelihood $\mathrm{p}$
\end{tabular}

Notes: Entries are known probabilities $\mathrm{q}_{\mathrm{i}} ; \mathrm{x}, \mathrm{y}$, and $\mathrm{E}$ are constant across choices in this list and depend on the treatment (see Table 1).

The inclusion of the basic comparison between $\mathrm{x}_{\mathrm{E}} \mathrm{y}$ and $\mathrm{x}_{\mathrm{p}} \mathrm{y}$ allows us to assess the robustness of the initial choice from stage 1, and in particular when it is included in a full list of choices. The comparison of the option selected in stage 1 and stage 2 for this choice item provides us with a measure for the consistency of ambiguity attitudes across tasks (Binmore et al. 2012; Charness et al. 2013). It is also an indication for the robustness of our results.

\subsection{Experimental Procedures}

Following the classic Ellsberg thought experiments, risky and ambiguous prospects are implemented as opaque bags which are filled with exactly 100 chips of different colors. In the moderate likelihood treatments $(\mathrm{p}=.5)$, bags contain at most two colors; in the low likelihood treatments $(\mathrm{p}=.1)$, bags contain at most ten different colors. At the beginning of the experiment, and before any instructions for stage 1 are handed out, we ask each 
participant to choose a personal "decision color" from the list of possible colors, which remains fixed throughout the experiment. At that point, participants are not aware of any experimental details, thus their beliefs about events in the Ellsberg tasks cannot affect their color choice. Participants are informed that the selected color will be relevant for determining their payoffs.

For the ambiguous prospect, an opaque bag has already been filled with 100 colored chips when subjects enter the laboratory. The distribution of colors is unknown to subjects as well as to the experimenters. However, we do allow participants to inspect this bag as soon as the experiment is over, and this is announced. ${ }^{2}$ For each risky prospect $\mathrm{x}_{\mathrm{q}} \mathrm{y}$ we prepare a bag that contains exactly $\mathrm{q}_{\mathrm{i}} \times 100$ red chips and $\left(1-\mathrm{q}_{\mathrm{i}}\right) \times 100$ chips of the remaining colors (either one other or nine other colors). Thus, the prospect pays $\mathrm{x}$ if a red chip is drawn from the respective bag, and y if another chip is drawn. In contrast, the ambiguous prospect pays $\mathrm{x}$ if a chip of the participant's personal decision color is drawn from the ambiguous bag, and y otherwise. By letting subjects choose their personal decision color it is obviously impossible for the experimenter to trick subjects or bias the distribution of colors in the ambiguous bag (Charness et al. 2013; Pulford 2009). In the instructions of each part, we remind subjects that they have chosen their decision color themselves. Further, to facilitate an understanding of risky prospects, the corresponding distributions of chips are placed on a table in the lab room, visible to participants during the experiment (see Figure A1 in Appendix A.2), before they are filled into bags to determine outcomes at the end of the experiment.

At the beginning of the experiment subjects receive an endowment of $€ 20$. This endowment is identical in all treatments to avoid any effects from variations in initial wealth. One stage of the experiment is randomly selected to be payoff relevant for all participants in a particular session at the end of the experiment. Within a choice list, if relevant, one decision item is randomly selected to be paid out. This selection is randomized at the individual level. Because the experiment was computerized (using z-

\footnotetext{
${ }^{2}$ Before the experiment, a student assistant blindly drew 100 chips from an opaque bag filled with in total roughly 1000 chips of all relevant colors. From the instructions subjects learn that a student assistant drew 100 chips from a bag that contains considerably more than 100 chips of all relevant colors.
} 
Tree; Fischbacher 2007), we aimed to ensure credibility regarding our procedures (i) by implementing prospects in a concrete and verifiable way; (ii) allowing subjects to define the ambiguous prospect through their individual decision color; and (iii) by randomly selecting one participant as an assistant at the end of the experiment. This person was in charge of randomly selecting the payoff-relevant stage, of filling the risky bags, and of finally drawing one chip out of each bag. Each step is performed in front of the other participants, and outcomes are entered on the assistant's computer screen. ${ }^{3}$ Any earnings are added to or subtracted from the initial endowment.

While subjects might earn up to $€ 40.00$ in the gain treatments, they might end up with zero income in the loss treatments. In order to smooth expected income across treatments at least slightly we added an effort task based on Raven's progressive matrices (Raven et al., 1998) at the end of the experiment, in which subjects could earn an additional amount, which is negative in the gain, and positive in the loss treatments. The effort stage of the experiment was announced after all stages and decisions described in this paper. ${ }^{4}$

We do not provide any feedback on the outcome of preceding stages during the experiment and instructions are generally not handed out until the previous task had been

\footnotetext{
${ }^{3}$ First, the assistant drew one ball out of an opaque bag containing three numbered balls to determine the payoff relevant stage. If stage 1 was selected, the assistant filled one opaque bag with the distribution of chips defining the risky prospect $\mathrm{x}_{\mathrm{p}} \mathrm{y}$. If stage 2 was selected, the assistant filled nine opaque bags, one for each decision item of the respective choice list. In total, ten different bags could be payoff relevant, one ambiguous and nine risky ones. She then drew one chip from each bag to determine the individual outcomes for everyone in the room. If applicable, the random item from the list is selected for each individual by the computer program before chips are drawn. The procedure is clearly described in the instructions at the beginning of the experiment.

${ }^{4}$ Subjects have to solve ten effort tasks, which presented them with $3 \times 3$ matrixes of graphical figures, with one cell left blank. Within 45 seconds, the subject had to select the correct figure out of six different options, filling in the blank to complete the logical sequence of the matrix. In the gain treatments subjects incur a loss for every incorrect answer; in the loss treatments subjects earn a positive amount for every correct answer; in the mixed treatments subjects either face positive, negative or no incentives, which depends on whether $\mathrm{x}_{\mathrm{p}} \mathrm{y}$ yields a negative, positive or zero expected value, respectively.
} 
finished. Sample instructions for the 20.50 treatment are provided in Appendix A.2. The instructions use neutral terms for all prospects.

\section{Data Description}

In total 501 subjects (invited with the organization software Orsee (Greiner 2004)) participated in 21 experimental sessions, with three sessions for each treatment condition. $58 \%$ of participants were female, the average age was 24.5 years, and $21 \%$ were economics or business students. The experiment lasted roughly one hour and participants earned on average $€ 22.30$ (approx. $\$ 29.30$ at the time the experiment was conducted).

We did not enforce single switching points in the choice list of stage 2, and as often observed, some subjects switched more than once between ambiguous and risky prospects when moving down the list. If the person chooses ambiguity in the first and risk in the last choice item (for gains and mixed prospects with $\mathrm{x}>0$; vice versa for losses and mixed prospects with $\mathrm{x}<0$ ), we deal with these violations of monotonicity by calculating the probability equivalent as the midpoint over the range defined by her first and by her last switching point. If the person does not start from ambiguous and eventually switch to and remain at risky, the midpoint is not defined, and we drop the respective observation from the sample of stage 2 choices. ${ }^{5}$ This leaves us with 289 stage 1 choices and 280 valid stage 2 probability equivalents in the pure outcome treatments, and 212 stage 1 choices and 204 valid stage 2 probability equivalents in the mixed outcome treatments.

We classify subjects as ambiguity averse or ambiguity seeking as follows. In the stage 1 direct choice, a subject is classified as ambiguity averse (seeking) if she prefers the risky (ambiguous) prospect. In stage 2, for gain treatments (and in mixed with $x>0$ ) a subject is classified as ambiguity averse (seeking) if the probability equivalent $\mathrm{q}$ is smaller than $\mathrm{p}$ (larger than $\mathrm{p}$ ). Analogously, in the loss treatments $(\mathrm{x}<0)$ a subject is

\footnotetext{
${ }^{5}$ Overall the rate of inconsistency was low: $5.8 \%$ of all choice lists involved inconsistencies $(5.2 \%$ in pure domains and $6.6 \%$ in mixed domains), and only $3.4 \%$ of all choice lists had to be dropped from the sample (3.1\% in pure domains and 3.8\% in mixed domains). These numbers are well within the bounds typically observed in empirical studies. Our results do not change substantially if we instead drop all choice lists involving multiple switching, or if we exclude stage 1 observations for those subjects who provided inconsistent lists in stage 2 (shown in Tables A4 and A5 in Appendix A.4).
} 
classified as ambiguity averse (seeking) if the probability equivalent $q$ is larger than $p$ (smaller than $\mathrm{p}$ ).

While binary choices in stage 1 do not allow identifying indifference between the ambiguous and risky prospect, ambiguity neutrality can be detected on the basis of stage 2 probability equivalents. Ambiguity neutrality implies indifference between risky and ambiguous prospect if and only if $\mathrm{q}=\mathrm{p}$ (where $\mathrm{p}=.5$ or $\mathrm{p}=.1$ ). Thus, ambiguity neutral subject will either switch in the decision item in which the known probability $\mathrm{q}_{\mathrm{i}}$ is equal to $\mathrm{p}$, or in the subsequent one. ${ }^{6}$ In the following we first provide results without specific consideration of ambiguity neutrality and then discuss its extent and its impact on the elicited pattern of attitudes in greater detail. We subsequently analyze the consistency of ambiguity attitudes across stages 1 and 2 .

\section{Ambiguity Attitudes for Pure Outcome Domains}

\subsection{Basic Results}

The left panel of Table 3 summarizes the results for the pure-domain treatments based on the whole sample. ${ }^{7}$ The table indicates the direction of ambiguity attitudes in each condition and stage (AA for ambiguity aversion; AS for ambiguity seeking; results that are insignificantly different from ambiguity neutrality in parentheses). We replicate the typical finding of ambiguity aversion in the classic Ellsberg setting (i.e., 20.50): a minority of $38.9 \%$ prefers the ambiguous prospect in stage 1 (binomial test, $\mathrm{p}=.076$; $\mathrm{N}=72$ ), and probability equivalents are modestly, but significantly smaller than .5.

In contrast, for the other outcome domains we do not find any evidence for ambiguity aversion. Behavior in the moderate likelihood loss domain is indistinguishable from ambiguity neutrality (defined here as $50 \%$ of subjects choosing either prospect in stage 1 , and $\mathrm{q}=.5$ in stage 2 ). For the two low-likelihood prospects we observe ambiguity

\footnotetext{
${ }^{6}$ That is, in the comparison between $\mathrm{q}_{\mathrm{i}}$ and $\mathrm{p}$ they may choose either option since they are indifferent. Details and a graphical representation of switching behavior consistent with ambiguity neutrality are provided in Appendix A.3.

${ }^{7}$ All hypothesis tests reported in the paper are two-sided tests. We acknowledge that the prediction of a fourfold pattern of attitudes generates one-sided hypotheses in the pure outcome domains. The interpretation of our results would not change if less conservative one-sided tests were used accordingly.
} 
seeking, although the preference is only statistically significant in stage 2 for 20.10 and in stage 1 for $(-20)_{.1} 0$. That is, considering all domains, there is no support for universal ambiguity aversion: Pooling all stage 1 choices from pure domain treatments does not indicate any ambiguity attitude (binomial test, $\mathrm{p}=.556 ; \mathrm{N}=289$ ). Classifying subjects as ambiguity averse or ambiguity seeking according to their probability equivalent, we again observe no significant tendency towards ambiguity aversion (binomial test, $\mathrm{p}=.106$; $\mathrm{N}=280$ ). However, we also observe that the pattern of attitudes shown in the left panel of Table 3 is not fully consistent with the fourfold pattern identified in the literature (shown in Table 1, column 6), because the pattern would predict ambiguity aversion for the (20)..$_{1} 0$ loss treatments. In contrast, significant ambiguity seeking is found in this domain.

Table 3: Ambiguity Attitudes for Pure Outcome Domains

\begin{tabular}{|c|c|c|c|c|c|c|}
\hline \multirow[b]{2}{*}{ Treatment } & \multicolumn{3}{|c|}{ Whole Sample } & \multicolumn{3}{|c|}{ Distinct from Neutrality ${ }^{b}$} \\
\hline & $\begin{array}{c}\text { \# obs. } \\
\text { Stage } 1 \\
\text { (Stage 2) }\end{array}$ & $\begin{array}{c}\text { Stage 1: } \\
\text { ambiguous } \\
\text { choices }(\%)\end{array}$ & $\begin{array}{c}\text { Stage } 2 \text { : } \\
\text { probability } \\
\text { equivalent }^{\mathrm{a}}\end{array}$ & $\begin{array}{c}\text { \# obs. } \\
\text { Stage } 1 \\
\text { (Stage } 2)\end{array}$ & $\begin{array}{c}\text { Stage 1: } \\
\text { ambiguous } \\
\text { choices }(\%)\end{array}$ & $\begin{array}{l}\text { Stage } 2 \text { : } \\
\text { probability } \\
\text { equivalent }^{\mathrm{a}}\end{array}$ \\
\hline 20.50 & $72(70)$ & $38.9 \mathrm{AA}^{*}$ & $.48 \mathrm{AA}^{* * *}$ & $26(26)$ & $15.4 \mathrm{AA}^{* * *}$ & $.43 \mathrm{AA}^{* * *}$ \\
\hline$(-20) .50$ & $73(71)$ & 47.9 (AA) & $.53(\mathrm{AA})$ & $17(16)$ & 64.7 (AS) & $.43 \mathrm{AS}^{* *}$ \\
\hline 20.10 & $71(67)$ & 57.7 (AS) & $.12 \mathrm{AS}^{* * *}$ & $21(20)$ & $71.4 \mathrm{AS}^{*}$ & $.15 \mathrm{AS}^{* * *}$ \\
\hline$(-20) .10$ & $73(72)$ & $63.0 \mathrm{AS}^{* *}$ & $.09(\mathrm{AS})$ & $25(24)$ & $28.0 \mathrm{AA}^{* *}$ & $.15 \mathrm{AA}^{*}$ \\
\hline
\end{tabular}

Notes: a: median reported; b: classification as described in section 3; direction of effect: AA = ambiguity aversion; AS $=$ ambiguity seeking; $*, * *, * * *$ denotes significance at the $10 \%, 5 \%$, and $1 \%$ level; stage 1 : two-sided binomial test against $\mathrm{p}=.5$; stage 2 : two-sided t-test against probability equivalent $\mathrm{q}=.5 / .1$.

\subsection{Accounting for Ambiguity Neutrality}

A significant share of the participants exhibits ambiguity neutrality as defined in section 3. Columns 1 to 4 in Table 4 show that the share of ambiguity neutral subjects in the pure outcome domains falls in the range $62.9 \%$ up to $77.5 \%$. These are large percentages. With respect to the basic Ellsberg domain 20.50 this suggests that while many subjects have a tendency to make ambiguity averse choices, the strength of these attitudes might in fact be modest. 
Table 4: Ambiguity Neutral Subjects by Treatment

\begin{tabular}{ccccccc}
\hline \hline 20.50 & $(-20)_{.5} 0$ & 20.10 & $(-20)_{.1} 0$ & $(-10)_{.5} 10$ & $(-10)_{.1}(10)$ & $10.1(-10)$ \\
$62.9 \%$ & $77.5 \%$ & $70.2 \%$ & $66.7 \%$ & $82.4 \%$ & $67.2 \%$ & $81.2 \%$ \\
\hline \hline
\end{tabular}

Notes: Entries report percentages of subjects with probability equivalent in the interval $[0.475,0.525]$ in treatments with moderate likelihoods, and in $[0.085,0.115]$ in treatments with low likelihoods. See section 3 for details.

As described in section 3, ambiguity neutral subjects may make choices in different ways that are both consistent with their attitudes and lead to different categorizations in terms of ambiguity attitude. This might affect the observed average patterns of attitudes in the four domains of interest. The right panel of Table 3 shows results including only those subjects who are not identified as ambiguity neutral according to our definition. Although the sample sizes are strongly reduced, a highly significant and consistent (across stages) pattern emerges: strong ambiguity aversion for moderate likelihood gains and low likelihood losses, and strong ambiguity seeking for moderate likelihood losses and low likelihood gains. That is, participants who are not ambiguity neutral strongly reveal the predicted fourfold pattern of ambiguity attitudes. Moreover, because the pattern obtains for both binary choices and probability equivalents, it seems unlikely that it is driven by choice list design effects that might have influenced previous results. However, we observe that the deviations from neutrality in the stage 2 task are much more modest than in some of the reports in the literature, suggesting that our design reduced biases in the elicitation methods.

\subsection{Consistency across Elicitation Tasks}

The consistency of ambiguity attitudes over repeated choices in the same experiment has been questioned in some studies (Binmore et al. 2012; Dürsch et al. 2013; Stahl 2014). The inclusion of the stage 1 choice between $\mathrm{x}_{\mathrm{E}} \mathrm{y}$ and $\mathrm{x}_{\mathrm{p}} \mathrm{y}$ in the stage 2 choice lists allows us to examine consistency on the individual level. Table 5 provides the results.

Overall consistency across stages is high, with the standard Ellsberg task 20.50 being at the lower end of the range of consistency rates with about $72 \%$ of participants choosing consistently. Ambiguity neutrals may choose differently in both stages simply because they are indifferent between the risky and the ambiguous prospect. However, excluding 
ambiguity neutral subjects, we find similar rates of consistency, with rates increasing in some treatments and decreasing in others.

Table 5: Consistency of Ambiguity Attitude

\begin{tabular}{lccccccc}
\hline \hline & 20.50 & $(-20) .50$ & 20.10 & $(-20) .10$ & $(-10) .510$ & $(-10) .110$ & $10.1(-10)$ \\
\hline $\begin{array}{l}\text { Including } \\
\text { ambiguity } \\
\text { neutrals }\end{array}$ & $72.9 \% *$ & $88.7 \% *$ & $82.1 \% *$ & $79.2 \% *$ & $72.1 \% *$ & $74.6 \% *$ & $78.3 \% *$ \\
$\begin{array}{l}\text { Excluding } \\
\text { ambiguity } \\
\text { neutrals }\end{array}$ & $88.5 \% *$ & $93.8 \% *$ & $80.0 \% *$ & $75.0 \% *$ & $75.0 \%$ & $63.6 \%$ & $92.3 \% *$ \\
\hline \hline $\begin{array}{l}\text { Notes: Entries report percentages of subjects who make consistent choice for the identical choice item in stage 1 and } \\
\text { stage 2 of the experiment. * indicates that the percentage is larger at the 5\% significance level than expected under } \\
\text { random choices (50\% consistency). }\end{array}$
\end{tabular}

\section{Ambiguity Attitudes in the Mixed Outcome Domain}

Under the benchmark assumption of universal ambiguity aversion, the mixed domain received little attention in ambiguity research. However, given results that emphasize the role of the outcome domain for ambiguity attitudes, the mixed domain becomes an important testing ground for models of ambiguity attitude that can account for domain specificity (Abdellaoui et al. 2011; Klibanoff et al. 2005; Tversky and Kahneman 1992). It also relates more directly to the type of prospects experienced by decision makers in financial markets, medical decisions, or decisions in legal contexts, for example.

We consider three mixed prospects: a symmetric prospect with an equal chance to win or lose $€ 10$; an advantageous prospect (-10).110 with a low likelihood loss and a high likelihood gain event; and a disadvantageous prospect $10_{.1}(-10)$ with a low likelihood gain and a high likelihood loss event. As Table 4 shows, there are many ambiguity neutral subjects also for the mixed outcome domain, and we therefore report results for both the whole sample and the sample restricted to subjects who are not classified as ambiguity neutral. Results are shown in Table 6.

Three main insights obtain from Table 6. First, there is little evidence of (universal) ambiguity aversion for mixed prospects either. Second, there is less consistency of the pattern of attitudes across stages than for the pure domains: neither the full nor the 
reduced sample reveals a consistent pattern for all three prospects. Third, the only robust finding concerns the ambiguity seeking observed for prospect $10_{.1}(-10)$.

Table 6: Ambiguity Attitudes for the Mixed Outcome Domain

\begin{tabular}{|c|c|c|c|c|c|c|}
\hline \multirow[b]{2}{*}{ Treatment } & \multicolumn{3}{|c|}{ Whole sample } & \multicolumn{3}{|c|}{ Distinct from Neutrality ${ }^{b}$} \\
\hline & $\begin{array}{c}\text { \# obs. } \\
\text { Stage } 1 \\
\text { (Stage } 2)\end{array}$ & $\begin{array}{c}\text { Stage 1: } \\
\text { ambiguous } \\
\text { choices }(\%)\end{array}$ & $\begin{array}{c}\text { Stage } 2 \text { : } \\
\text { probability } \\
\text { equivalent }^{\mathrm{a}}\end{array}$ & $\begin{array}{c}\text { \# obs. } \\
\text { Stage } 1 \\
\text { (Stage } 2 \text { ) }\end{array}$ & $\begin{array}{c}\text { Stage 1: } \\
\text { ambiguous } \\
\text { choices }(\%)\end{array}$ & $\begin{array}{l}\text { Stage 2: } \\
\text { probability } \\
\text { equivalent }^{2}\end{array}$ \\
\hline$(-10) .510$ & $73(68)$ & $34.2 \mathrm{AA}^{* * *}$ & $.53(\mathrm{AA})$ & $16(12)$ & $37.5(\mathrm{AA})$ & .43 (AS) \\
\hline$(-10) .110$ & $69(67)$ & $58.0(\mathrm{AS})$ & $.12 \mathrm{AA}^{* * *}$ & $23(22)$ & 56.5 (AS) & $.15 \mathrm{AA}^{* *}$ \\
\hline $10_{.1}(-10)$ & 70 (69) & $67.1 \mathrm{AS}^{* * *}$ & $.12 \mathrm{AS}^{* *}$ & $13(13)$ & 84.6 AS** & $.15 \mathrm{AS}^{* *}$ \\
\hline
\end{tabular}

\section{Discussion}

In this paper we elicit ambiguity attitudes of more than 500 participants in four pure and three mixed outcome domains, at different levels of likelihood. Our measurement methods were designed to minimize biases caused by the elicitation method. In particular, we aimed to provide a conservative test of the ambiguity seeking tendencies observed in the previous literature. We also minimized design heterogeneity across domains: heterogeneity in terms of payoffs (real vs. hypothetical; endowment vs. no endowment), in terms of the presentation of the ambiguous prospects (Ellsberg urns, second order probabilities), and in terms of the degree to which participants' beliefs about the distribution of colors in the Ellsberg urns are controlled for.

We find no evidence for universal ambiguity aversion as it is assumed by basically all theoretical applications in various subfields of economics and finance today. In contrast, ambiguity attitudes are domain-specific and depend on likelihood ranges. A large share of the participants in our experiments can be categorized as ambiguity neutral. For those subjects who reveal clear deviation from neutrality, a fourfold pattern of ambiguity attitudes strongly emerges from the data: Ambiguity aversion is found for modest likelihood gain (as in the classic Ellsberg paradox) and low likelihood loss prospects. Ambiguity seeking is found for low likelihood gain prospects and modest 
likelihood loss prospects. In all domains, a large group of subjects (a majority in fact) is close to ambiguity neutrality. This observation relates to the importance of individual heterogeneity in ambiguity attitudes (demonstrated for market outcomes in Bossaerts et al. 2010; Tymula et al. 2013), across all domains of interest. Overall, when looking at our evidence, the conclusion that ambiguity aversion is more an exception rather than the rule seems to be vindicated.

We find high but not perfect rates of consistency across stage 1 and stage 2 choices in our experiment. The finding suggests that choice list format does affect respondents' decisions. Consequently, estimates of the absolute degree(s) of ambiguity aversion observed in some specific measurement should be interpreted with care: these levels will be affected by idiosyncratic design effects. In contrast, as long as general patterns and comparative results are the researcher's objective, more robustness can be expected.

Finally, with virtually all relevant problems in economics and finance relating to the mixed outcome domain, more empirical investigation of this domain seems warranted. We provide a first measurement of ambiguity attitudes for mixed prospects. As for the pure domains, we find little evidence of universal ambiguity aversion. Results seem also less robust, however, than those for the pure domains. The challenge for descriptive theoretical work on ambiguity will be to provide a model that can account for both the pattern observed for the pure domains, as well as for the attitudes revealed in the mixed domain. To allow researchers to test or calibrate their models, our comprehensive data set of binary choices and certainty equivalents in the pure and mixed domains will be made available online. $^{8}$

\footnotetext{
${ }^{8}$ The data will be deposited at https://heidata.uni-heidelberg.de/dvn/dv/awiexeco.
} 


\section{References}

Abdellaoui, Mohammed, Aurélien Baillon, Laetitia Placido, and Peter P. Wakker. 2011. “The Rich Domain of Uncertainty." American Economic Review, 101(2): 695-723.

Abdellaoui, Mohammed, Frank Vossmann, and Martin Weber. 2005. "Choice-Based Elicitation and Decomposition of Decision Weights for Gains and Losses under Uncertainty." Management Science, 51(9): 1384-1399.

Alary, David, Christian Gollier, and Nicolas Treich. 2013. "The Effect of Ambiguity Aversion on Insurance and Self-protection." The Economic Journal, 123(573): $1188-1202$.

Baillon, Aurélien, and Han Bleichrodt. 2015. "Testing Ambiguity Models through the Measurement of Probabilities for Gains and Losses." American Economic Journal: Microeconomics, forthcoming.

Berger, Loïc, Han Bleichrodt, and Louis Eeckhoudt. 2013. "Treatment Decisions under Ambiguity." Journal of Health Economics, 32(3): 559-569.

Binmore, Ken, Lisa Stewart, and Alex Voorhoeve. 2012. "How Much Ambiguity Aversion? Finding Indifferences between Ellsberg's Risky and Ambiguous Bets." Journal of Risk and Uncertainty, 45(3): 215-238.

Bossaerts, Peter, Paolo Ghirardato, Serena Guarnaschelli, and William Zame. 2010. "Prices and Allocations in Asset Markets with Heterogeneous Attitudes Toward Ambiguity." Review of Financial Studies 23(4): 1325-1359.

Budescu, David V., Kristine M. Kuhn, Karen M. Kramer, and Timothy R. Johnson. 2002. "Modeling Certainty Equivalents for Imprecise Gambles." Organizational Behavior and Human Decision Processes, 88(2): 748-768.

Charness, Gary, Edi Karni, and Dan Levin. 2013. "Ambiguity Attitudes and Social Interactions: An Experimental Investigation." Journal of Risk and Uncertainty, 46(1): 1-25. 
Cohen, Michèle, Jean-Yves Jaffray, and Tanios Said. 1987. "Experimental Comparisons of Individual Behavior under Risk and under Uncertainty for Gains and for Losses." Organizational Behavior and Human Decision Processes, 39(1): 1-22.

Collard, Fabrice, Sujoy Mukerji, Kevin Sheppard, and Jean-Marc Tallon. 2011. “Ambiguity and the Historical Equity Premium”. CES Working Paper No. 2011.32.

Di Mauro, Carmela, and Anna Maffioletti. 2004. "Attitudes toward Risk and Attitudes toward Uncertainty: Experimental Evidence.” Applied Economics, 36(4): 357-372.

Dow, James, and Sérgio Ribeiro da Costa Werlang. 1992. "Uncertainty Aversion, Risk Aversion, and the Optimal Choice of Portfolio.” Econometrica, 60(1): 197-204.

Dürsch, Peter, Daniel Römer, and Benjamin Roth. 2013. "Intertemporal Stability of Ambiguity Preferences.” Working Paper, University of Heidelberg.

Easley, David, and Maureen O'Hara. 2009. “Ambiguity and Nonparticipation: The Role of Regulation.” Review of Financial Studies, 22(5): 1817-1843.

Einhorn, Hillel J., and Robin M. Hogarth. 1986. "Decision Making under Ambiguity." Journal of Business, 59(2): S225-S250.

Ellsberg, Daniel. 1961. "Risk, Ambiguity and the Savage Axioms." Quarterly Journal of Economics, 75(4): 643-669.

Ellsberg, Daniel. 2011. "Notes on the Origin of the Ellsberg Urns (Introduction to the Symposium Issue).” Economic Theory, 48(2-3): 221-227.

Farber, Daniel A. 2011. "Uncertainty." Georgetown Law Journal, 99: 901-959.

Fischbacher, Urs. 2007. "z-Tree: Zurich Toolbox for Ready-made Economic Experiments.” Experimental Economics, 20(2): 171-178.

Gollier, Christian. 2011. "Portfolio Choices and Asset Prices: The Comparative Statics of Ambiguity Aversion.” The Review of Economic Studies, 78(4): 1329-1344.

Greiner B. 2004. "An Online Recruitment System for Economic Experiments.” In: Kremer, K., Macho, V. (Eds.). Forschung und wissenschaftliches Rechnen 2003, GWDG Bericht 63. Göttingen: 79-93. 
Hoy, Michael, Richard Peter, and Andreas Richter. 2014. "Take-up for Genetic Tests and Ambiguity." Journal of Risk and Uncertainty, 48(2): 111-133.

$\mathrm{Ju}$, Nengjiu, and Jianjun Miao. 2012. "Ambiguity, Learning, and Asset Returns." Econometrica, 80(2): 559-591.

Kahn, Barbara E., and Rakesh K. Sarin. 1988. "Modeling Ambiguity in Decisions under Uncertainty.” Journal of Consumer Research, 15(2): 265-272.

Keren, Gideon B., and Léonie E. M. Gerritsen. 1999. "On the Robustness and Possible Accounts of Ambiguity Aversion.” Acta Psychologica, 103(1): 149-172.

Klibanoff, Peter, Massimo Marinacci, and Sujoy Mukerji. 2005. "A Smooth Model of Decision Making under Ambiguity." Econometrica 73(6): 1849-1892.

Levy, Ifat, Jason Snell, Amy J. Nelson, Aldo Rustichini, and Paul W. Glimcher. 2010. "Neural Representation of Subjective Value under Risk and Ambiguity." Journal of Neurophysiology, 103(2): 1036-1047.

Maenhout, Pascal J. 2004. "Robust Portfolio Rules and Asset Pricing." Review of Financial Studies, 17(4): 951-983.

Millner, Antony, Simon Dietz, and Geoffrey Heal. 2013. "Scientific Ambiguity and Climate Policy." Environmental and Resource Economics, 55(1): 21-46.

Pulford, Briony D. 2009. "Is Luck on My Side? Optimism, Pessimism, and Ambiguity Aversion.” Quarterly Journal of Experimental Psychology, 62(6): 1079-1087.

Raven, John, John C. Raven, and John H. Court. 2000. “Manual for Raven’s Progressive Matrices and Vocabulary Scales.” Oxford: Oxford Psychologists Press.

Snow, Arthur. 2011. "Ambiguity Aversion and the Propensities for Self-insurance and Self-protection." Journal of Risk and Uncertainty, 42(1): 27-43.

Stahl, Dale O. 2014. "Heterogeneity of Ambiguity Preferences." Review of Economics and Statistics, 96(4): 609-617 
Trautmann, Stefan T., and Gijs van de Kuilen. 2014. "Ambiguity Attitudes." Forthcoming. In: Keren, G., Wu, G. (Eds.), Blackwell Handbook of Judgment and Decision Making (Chapter 3), Blackwell.

Tversky, Amos, and Daniel Kahneman. 1992. "Advances in Prospect Theory: Cumulative Representation of Uncertainty." Journal of Risk and Uncertainty, 5(4): 297-323.

Tymula, Agnieszka, Lior A. Rosenberg Belmaker, Lital Ruderman, Paul W. Glimcher, and Ifat Levy. 2013. "Like Cognitive Function, Decision Making across the Life Span Shows Profound Age-related Changes." Proceedings of the National Academy of Sciences, 110(42): 17143-17148.

Vieider, Ferdinand M., Peter Martinsson, and Haileselassie Medhin. 2012. "Stake Effects on Ambiguity Attitudes for Gains and Losses.” Working Paper, WZB Berlin. 


\section{Appendix}

\section{A.1. Review of Ambiguity Measurements across Outcome and Likelihood Domains}

To provide a benchmark for the evaluation of the current design and results, Table A1 gives a concise summary of previous studies that examined ambiguity attitudes in the four domains of to the current study (gains vs. loss outcomes; moderate vs. low likelihood events). The table illustrates the strong design heterogeneity within and across studies, and also shows the emerging evidence for the fourfold pattern of ambiguity attitude with ambiguity aversion for modest likelihood gains and low likelihood losses, and ambiguity seeking for low likelihood gains and modest likelihood losses. For a broader review, including studies that only consider a subset of these domains, we refer to the review chapter by Trautmann and van de Kuilen (2014). 
Table A1: Design Properties and Findings of Experimental Measurements of Ambiguity Attitude

\begin{tabular}{|c|c|c|c|c|c|c|}
\hline Paper & $\begin{array}{c}\text { Ellsberg design } \\
\text { (Controls for belief and trust if Ellsberg } \\
\text { stimuli if other than Ellsberg) }\end{array}$ & Elicitation method & $\begin{array}{l}\text { Real incentives for all } \\
\text { conditions } \\
\text { (identical endowments) }\end{array}$ & $\begin{array}{l}\text { Between- or within- } \\
\text { subjects design }\end{array}$ & $\begin{array}{l}\text { \# of subjects } \\
\text { (Country) }\end{array}$ & $\begin{array}{l}\text { Fourfold } \\
\text { pattern } \\
\text { reported }\end{array}$ \\
\hline $\begin{array}{l}\text { Abdellaoui et al. } \\
(2005)\end{array}$ & No (variation in stock index) & $\begin{array}{l}\text { Elicit Cumulative } \\
\text { Prospect Theory decision } \\
\text { weighting functions }\end{array}$ & No & Within & $\begin{array}{c}41 \\
\text { (Germany) }\end{array}$ & Yes \\
\hline $\begin{array}{l}\text { Baillon and } \\
\text { Bleichrodt (2015) }\end{array}$ & No (variation in stock indices) & $\begin{array}{l}\text { Choice list for probability } \\
\text { equivalents }\end{array}$ & Yes (Yes) & Within & $\begin{array}{c}37 \\
\text { (Netherlands) }\end{array}$ & Yes \\
\hline $\begin{array}{l}\text { Budescu et al. } \\
\text { (2002) }\end{array}$ & No (vague probabilities) & Certainty equivalents & Yes & Within & $\begin{array}{c}23 \\
\text { (USA) }\end{array}$ & No \\
\hline $\begin{array}{l}\text { Di Mauro and } \\
\text { Maffioletti } \\
(2004)\end{array}$ & $\begin{array}{l}\text { No (expert guess on unknown } \\
\text { likelihoods) }\end{array}$ & $\begin{array}{l}\text { Second price auctions to } \\
\text { insure against a loss or to } \\
\text { assure a gain }\end{array}$ & Yes (No) & $\begin{array}{l}\text { Within (probabilities) } \\
\text { and between (outcomes) }\end{array}$ & $\begin{array}{l}116 \\
(\mathrm{UK})\end{array}$ & Yes \\
\hline $\begin{array}{l}\text { Einhorn and } \\
\text { Hogarth (1986) }\end{array}$ & Yes $(\mathrm{N})$ & $\begin{array}{l}\text { Direct choice between } \\
\text { risk and ambiguity }\end{array}$ & No & $\begin{array}{l}\text { Within (probabilities) } \\
\text { and between (outcomes) }\end{array}$ & $\begin{array}{c}274 \\
\text { (USA) }\end{array}$ & No \\
\hline $\begin{array}{l}\text { Kahn and Sarin } \\
\text { (1988) }\end{array}$ & $\begin{array}{l}\text { No ("ambiguous versus } \\
\text { unambiguous probabilities" in } \\
\text { consumer context choices) }\end{array}$ & $\begin{array}{l}\text { Direct choice between } \\
\text { risk and ambiguity }\end{array}$ & Yes (No) & Within & $\begin{array}{c}60 \\
\text { (USA) }\end{array}$ & Yes \\
\hline $\begin{array}{l}\text { Keren and } \\
\text { Gerritsen (1999) }\end{array}$ & Yes (CC) & $\begin{array}{l}\text { Direct choice between } \\
\text { risk and ambiguity }\end{array}$ & No & Between & $\begin{array}{c}258 \\
\text { (Netherlands) }\end{array}$ & No \\
\hline $\begin{array}{l}\text { Vieider et al. } \\
(2012)\end{array}$ & Yes $(\mathrm{N})$ & $\begin{array}{l}\text { Choice lists for certainty } \\
\text { equivalents }\end{array}$ & Yes (No) & Within & $\begin{array}{c}157 \\
\text { (Ethiopia) }\end{array}$ & Yes \\
\hline This Paper & Yes $(\mathrm{FC})$ & $\begin{array}{l}\text { Direct choice between } \\
\text { risk and ambiguity \& } \\
\text { choice list for probability } \\
\text { equivalents }\end{array}$ & Yes (Yes) & Between & $\begin{array}{c}501 \\
\text { (Germany) }\end{array}$ & Yes \\
\hline
\end{tabular}

Notes: The table reports relevant design properties and findings for measurements of ambiguity attitudes that consider all four outcome $\times$ likelihood domains. a: N=not controlling for beliefs and trust; $\mathrm{CC}=$ color choice control for trust; $\mathrm{FC}=$ fully controlling for trusts and skewed beliefs. 


\title{
A.2 Instructions for the treatment for gains with moderate likelihoods $\left(20_{0.5} 0\right)$
}

\author{
Welcome to the experiment and thank you for your participation! \\ Please do not talk to other participants of the experiment from now on.
}

\section{General information on the procedure}

This experiment is conducted to investigate economic decision making. You can earn money during the experiment. It will be paid to you privately and in cash after the experiment.

The entire experiment lasts about 1 hour and consists of 4 parts. At the beginning of each part you will receive detailed instructions. If you have questions after the instructions or during the experiment please raise your hand. One of the experimenters will then answer your question privately. During the experiment you will be asked to make decisions. Your own decisions will determine your payment which is a result of the following rules. While you will be making your decisions a clock will count down at the right upper corner of the screen. This provides you with an indication about how much time you should spend on your decisions. Of course you can take more time if you need to; this might be especially likely in the beginning of the experiment. Only the information screens where no decisions need to be made will disappear after the time has run out.

Payment: In each part of the experiment your income is directly stated in Euro. Of Part I, Part II, and Part III only one part will be paid out. One participant will select which of those parts will be payoff relevant, randomly and with equal probability at the end of the experiment (after Part IV). As you do not know which part will be chosen, it is optimal for you to behave like each part was to be paid. Part IV is definitely relevant for your payment.

In the beginning of the experiment you will also receive an endowment of 20 Euro. Your total income is then equal to the sum of your endowment, the income of the selected part (I, II, or III), and of Part IV.

Anonymity: We evaluate any data of the experiment only in aggregate form and never connect personal information to individual data. At the end of the experiment you have to sign a receipt for the payment. This only serves for our internal accounting.

Devices: At your place you find a pen. Please leave it on the table after the experiment.

Start: In the beginning of the experiment we ask you to choose a color which will be your personal decision color during the experiment. In the following instructions you will learn how this color is important in determining payments.

On the first screen a list of colors is displayed. Please mark exactly one of those colors and confirm your choice by clicking the OK-button in the lower part of the screen. All participants choose from the same list of colors. As soon as every participant has chosen her personal decision color the instructions for the first part of the experiment will be distributed. 


\section{Part I}

\section{Task}

In this part you have to choose between two prospects. These prospects are described by two opaque bags, bag A and bag B. From each of these bags one chip is randomly drawn which will determine your payment as described further below. You choose whether your chip should be drawn from bag A or from bag B.

Bag A: Bag A has already been filled with exactly 100 colored chips before the experiment. These chips are either red or blue. The distribution of the colors is unknown to you: A student assistant has randomly drawn 100 chips from a bigger bag that contained far more than 100 chips - only red and blue ones. Thus, you do not know how many of the 100 chips are red or blue.

If you choose bag $\mathrm{A}$, you receive 20 Euro if the color of the chip that will be drawn from bag $\mathrm{A}$ is equal to you personal decision color, and 0 Euro if the chip has a different color.

Bag B: In a moment we will fill exactly 100 chips into bag B. Of those chips, exactly 50 are red and the remaining 50 are blue.

If you choose bag B, you receive 20 Euro if the color of the chip that will be drawn from bag B is red, and 0 Euro if the chip is not red.

Part I ends as soon as everyone has made her decision; you will then receive the instructions for Part II.

\section{Random draw of the chips at the end of the experiment}

After the completion of Part IV the computer will randomly assign two participants as assistants. One assistant will first draw a ball from a bag filled with three balls - numbered from 1 to 3 . The number of that ball determines the payoff relevant part.

If Part I is selected for payment the assistant will draw one chip from each of the bags A and B. The colors of these chips are then relevant for your payment (depending on whether you have chosen bag A or bag B). The other assistant will enter the color of the chips on her screen. Whether you have been assigned the role of an assistant will be shown to you on your screen at that point.

\section{Part II}

\section{Task}

In this part you will receive in total 9 decision problems. These will be displayed to you simultaneously on one screen. In each of these problems you choose between two prospects which we will again describe by two opaque bags.

In each of these problems you decide between bag A from Part I and a second bag, denoted by bag C. Bag $\mathrm{C}$ also contains exactly 100 - only red and blue - chips. How many of the chips are red and blue will be displayed on your screen.

To remind you: bag A has been randomly filled with 100 chips before the experiment. These chips are either red or blue. You do not know how many are red and how many are blue.

The decision problem from stage 1 is one example for a possible decision problem in this part. Another example is illustrated in the following table: 


\begin{tabular}{|l|l|l|}
\hline Bag A & Bag C & Your decision \\
\hline $\begin{array}{l}\text { Bag A contains exactly 100 chips; you do } \\
\text { not know how many are red or blue. }\end{array}$ & $\begin{array}{l}\text { Bag C contains exactly 100 chips of which } \\
\text { exactly } 40 \text { are of red color. }\end{array}$ & BAG A \\
$\begin{array}{l}\text { If a chip is drawn that is of your personal } \\
\text { decision color, you receive 20 Euro. If a } \\
\text { different chip is drawn, you receive 0 Euro. }\end{array}$ & $\begin{array}{l}\text { If a red chip is drawn, you receive 20 Euro. } \\
\text { If a different chip is drawn, you receive 0 } \\
\text { Euro. }\end{array}$ & OR \\
\hline
\end{tabular}

Your decision is not valid before you have made a choice for all decision problems and then clicked on the OK-button in the lower part of the screen. Take enough time for your decisions, as each decision can determine your payment from this part.

If Part II is selected as payoff relevant, your income from this part will be determined as follows: for each participant the computer selects randomly and with equal probability one of the 9 decision problems (i.e. each with a probability of 1/9). Each bag $\mathrm{C}$ will be filled with the corresponding number of red and blue chips. One assistant will draw one chip from each of these bags, and one chip from bag A, which will determine your payment as described above.

If, for example, the upper decision problem is chosen and you have chosen bag $\mathrm{C}$ you will receive 20 Euro if the chip from this bag is red, and 0 Euro if it is not red. If you have chosen bag A you receive 20 Euro if the chip from this bag is of your personal decision color that you have chosen yourself in the beginning.

Since you do not know which of the 9 decision problems will be selected for payment, it is optimal for you to behave as if each decision problem was relevant for payment.

Instructions for Part III and IV can be received from the authors upon request. 
Figure A1: Picture of the Lab Room (Top) and Colored Chips (Bottom)
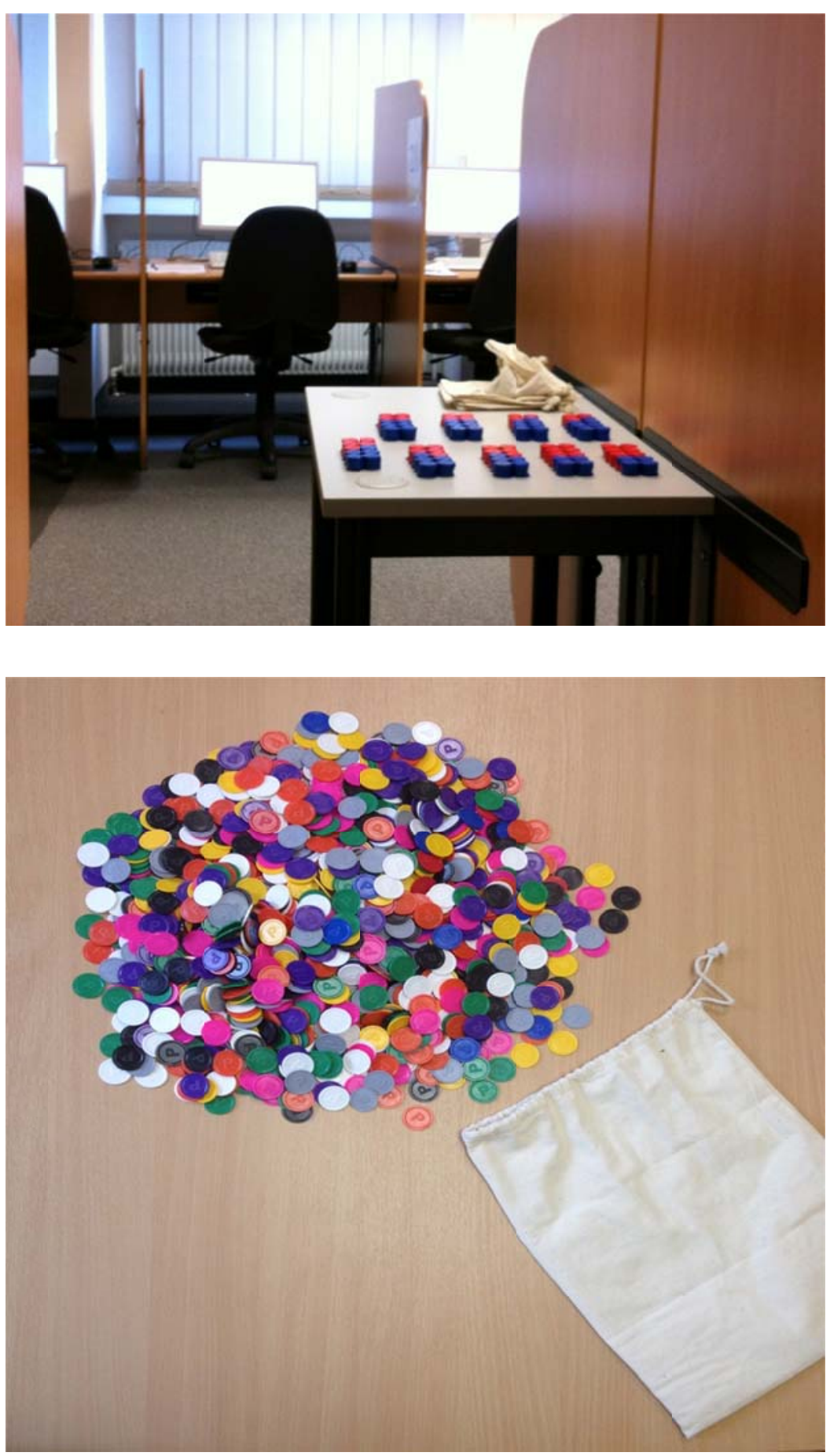


\section{A.3 Definition of Ambiguity Neutrality}

Table A3 demonstrates the possible decisions of ambiguity neutral subjects in the stage 2 choice lists. Because the subject is indifferent between the risky and ambiguous prospect in the decision item which is framed by dashed lines, she may choose either prospect in this choice item. Hence, switching may either occur already in that row (choice indicated by parentheses), or in the next decision item (choice indicated by square brackets).

Table A3: Switching Points for Ambiguity Neutral Subjects

\begin{tabular}{|c|c|c|c|c|c|}
\hline \multicolumn{3}{|c|}{$p=.5$} & \multicolumn{3}{|c|}{$\mathrm{p}=.1$} \\
\hline & Choice & $\begin{array}{c}\text { Risky } \\
\text { prospect with } \\
\text { prob. } \mathrm{q}_{\mathrm{i}}\end{array}$ & & Choice & $\begin{array}{c}\text { Risky } \\
\text { prospect with } \\
\text { prob. } \mathrm{q}_{\mathrm{i}}\end{array}$ \\
\hline \multirow{9}{*}{$\begin{array}{c}\text { Ambiguous } \\
\text { prospect }\end{array}$} & $\mathrm{X}$ & .25 & \multirow{9}{*}{$\begin{array}{c}\text { Ambiguous } \\
\text { prospect }\end{array}$} & $\mathrm{x}$ & .01 \\
\hline & $\mathrm{x}$ & .30 & & $\mathrm{x}$ & .04 \\
\hline & $\mathrm{x}$ & .35 & & $\mathrm{x}$ & .07 \\
\hline & $\mathrm{x}$ & .40 & & $(\mathrm{x}) \triangle[\mathrm{x}]$ & .10 \\
\hline & $\mathrm{x}$ & .45 & & $\mathrm{x}$ & .13 \\
\hline & $(x)-[x$ & .50 & & $\mathrm{x}$ & .16 \\
\hline & $\mathrm{x}$ & .55 & & $\mathrm{x}$ & .19 \\
\hline & $\mathrm{x}$ & .60 & & $\mathrm{x}$ & .22 \\
\hline & $\mathrm{x}$ & .65 & & $\mathrm{x}$ & .25 \\
\hline
\end{tabular}




\section{A.4 Supplementary Tables}

Table A4: Ambiguity Attitudes for Restricted Samples in Stage 1 and Stage 2

\begin{tabular}{lcccc}
\hline \hline & $\begin{array}{c}\text { \# obs. } \\
\text { Stage 1 } \\
\text { and 2 }\end{array}$ & $\begin{array}{c}\text { Stage 1: } \\
\text { ambiguous } \\
\text { choices (\%) }\end{array}$ & $\begin{array}{c}\text { Stage 2: } \\
\text { probability } \\
\text { equivalent }^{\mathrm{a}}\end{array}$ & $\begin{array}{c}\text { Consistent between } \\
\text { Stage 1 and 2 }(\%)\end{array}$ \\
\hline 20.5 & 70 & $37.1 \mathrm{AA}^{* *}$ & $.48 \mathrm{AA}^{* * *}$ & 72.9 \\
$(-20)_{.5} 0$ & 71 & $49.3(\mathrm{AA})$ & $.53(\mathrm{AA})$ & 88.7 \\
20.1 & 67 & $55.2(\mathrm{AS})$ & $.12 \mathrm{AS}^{* * *}$ & 82.1 \\
$(-20)_{.10} 0$ & 72 & $62.5 \mathrm{AS} * *$ & $.09(\mathrm{AS})$ & 79.2 \\
\hline \hline
\end{tabular}

Notes: a: median reported; b: classification as described in section 4.3; direction of effect: $\mathrm{AA}=$ ambiguity aversion; $\mathrm{AS}=$ ambiguity seeking; $* * *, * * *$ denotes significance at the $10 \%, 5 \%$, and $1 \%$ level; stage 1: two-sided binomial test against $\mathrm{p}=.5$; stage 2 : two-sided t-test against probability equivalent $=.5 / .1$.

Data of subjects who violate consistency criteria in stage 2 excluded in stages 1 and 2.

Table A5: Ambiguity Attitudes for Consistent Subjects

\begin{tabular}{lcccc}
\hline \hline & $\begin{array}{c}\text { \# obs. } \\
\text { Stage 1 } \\
\text { and 2 }\end{array}$ & $\begin{array}{c}\text { Stage 1: } \\
\text { ambiguous } \\
\text { choices (\%) }\end{array}$ & $\begin{array}{c}\text { Stage 2: } \\
\text { probability } \\
\text { equivalent }^{\mathrm{a}}\end{array}$ & $\begin{array}{c}\text { Consistent between } \\
\text { Stage 1 and } 2^{\mathrm{b}}(\%)\end{array}$ \\
\hline 20.50 & 51 & $17.6 \mathrm{AA}^{* * *}$ & $.48 \mathrm{AA}^{* * *}$ & 100.0 \\
$(-20)_{.5} 0$ & 63 & $47.6(\mathrm{AA})$ & $.53(\mathrm{AA})$ & 100.0 \\
20.10 & 55 & $60.0(\mathrm{AS})$ & $.12 \mathrm{AS}^{* * *}$ & 100.0 \\
$(-20) .10$ & 57 & $56.1(\mathrm{AS})$ & $.09(\mathrm{AS})$ & 100.0 \\
\hline \hline
\end{tabular}

Notes: a: median reported; b: classification as described in section 4.3; direction of effect: $\mathrm{AA}=$ ambiguity aversion; $\mathrm{AS}=$ ambiguity seeking; $* * *, * * *$ denotes significance at the $10 \%, 5 \%$, and $1 \%$ level; stage 1 : two-sided binomial test against $\mathrm{p}=.5$; stage 2 : two-sided t-test against probability equivalent $=.5 / .1$.

Data of subjects who violate consistency criteria in stage 2 and whose choices in stage 1 and stage 2 are not consistent excluded in stages 1 and 2 . 